\title{
Cartografia do lugar de moradia dos adolescentes com passagem pelo Cense I de Londrina
}

\author{
Cartography of the place of housing of the adolescents with ticket for Cense I of native of \\ Londrina
}

\author{
Claudemir Zulim * \\ Dione Lolis **
}

\begin{abstract}
Resumo:
Este artigo apresenta os resultados da análise dos dados documentais obtidos na pesquisa realizada no Centro de Socioeducação I - CENSE I, de Londrina, que objetiva identificar, mapear e analisar as condições socioespaciais dos bairros de origem dos adolescentes com passagem pela Unidade. O CENSE I é uma unidade de internação provisória por onde passam todos os adolescentes apreendidos em flagrante de ato infracional encaminhados à autoridade policial competente, que avalia se eles serão liberados para seus familiares ou se, de acordo com a gravidade dos fatos, serão ouvidos pelo representante do Ministério Público, enquanto aguardam a realização das oitivas junto ao Juízo da Vara da Infância e Juventude. Analisa os dados sobre o lugar de moradia dos adolescentes com passagem pela Unidade no ano de 2009. Utiliza as técnicas de Cartografia e de programas específicos com os quais foram produzidos gráficos e mapas onde são facilmente visualizados os locais de residência desses adolescentes. Verifica que os locais de maior concentração de adolescentes com passagem pelo CENSE I também concentram graves problemas socioespaciais, geralmente ligados a ocupações irregulares e em fundos de vale.
\end{abstract}

Palavras-chave: Cartografia. Lugar de residência. Adolescentes em conflito com a lei. Ato infracional. Socioeducação.

\begin{abstract}
:
This article presents the results of the analysis of documental data obtained in a search realized on Center of Social Education I - CENSE I, in Londrina, which aims recognize, map and analyze the social-spatial conditions of the adolescents original neighborhoods with passage in the Unity. The CENSE I is a provisory internment unity where are passed all the adolescents apprehended in flagrant on a infraction act and sent to the competent police authority, who evaluates if they will be released to their familiars or in accord with the gravity of facts, they will be listen by the representing of Public Ministry, while they wait the interviews for the
\end{abstract}

\footnotetext{
* Geógrafo, Especialista em Gestão de Centros de Socioeducação pela Universidade Estadual de Londrina. UEL/PR, Educador Social do Centro de Socioeducação I de Londrina. CENSE I zulim claudemir@yahoo.com.br

** Assistente social, mestrado em Serviço Social pela Pontifícia Universidade Católica de São Paulo e doutorado em Sociologia pela Universidade Estadual Paulista Júlio de Mesquita Filho Atualmente é professora adjunta da Universidade Estadual de Londrina. dionelolis@uel.br
} 
realization of hearings beside the Court of the Childhood and Adolescence. Analyzes the data about the dwelling place of adolescents with passage by the Unity on the year of 2009. Uses the techniques of Cartography and specific programs with which were produced tables and maps where are easily visualized the places of residence of these adolescents. Checks that the places of major concentration of adolescents with passage by CENSE I also concentrate serious social-spatial problems, generally linked to irregular occupations and in valley bottoms.

Keywords: Cartography. Place of residence. Adolescents in conflict with the law. Infraction act. Social education.

\section{Introdução}

Esta pesquisa foi realizada na Unidade de socioeducação denominada Centro de Socioeducação - CENSE I, de Londrina - Paraná, localizada em uma área residencial, no Jardim Pérola, na região Leste da cidade. Este estudo trata-se sobre o lugar de moradia dos adolescentes com passagem pela instituição e as condições socioespaciais do lugar. Preocupação que surge após anos de trabalho junto aos socioeducandos na referida Unidade, a partir do mapeamento, do aprofundamento teórico, e do conhecimento da realidade na busca de novas metodologias de intervenção.

Esta pesquisa se justifica pela necessidade de um estudo atual dos bairros do município de Londrina, onde concentram-se os maiores índices de residências de adolescentes com passagem pelo CENSE I. Analisamos dados referentes ao ano de 2009.

Na cidade estão instalados dois Centros de Socioeducação, o CENSE I, que é uma unidade de internação provisória, por onde passam todos os adolescentes apreendidos pela polícia, e o CENSE II, que é uma unidade em que o adolescente é internado para cumprir medida por ato infracional. Nesta fase, o adolescente já foi ouvido pelo juiz e já está cumprindo uma sentença que, segundo o Estatuto da Criança e do Adolescente ECA (BRASIL, 2006), consiste em medida a ser aplicada ao adolescente devendo ser avaliada a cada seis meses.

No CENSE I, a autoridade policial competente (Delegado) avalia, de acordo com a gravidade da infração, se o adolescente pode ser entregue a seus familiares ou se considera conveniente, e de acordo com o ECA, que ele permaneça internado 
provisoriamente e seja ouvido pelo representante do Ministério Público (Promotor de Justiça) enquanto aguarda para ser ouvido. ${ }^{1}$

A Unidade foi construída originalmente para abrigar os adolescentes com determinação de internação provisória, e hoje atende também a adolescentes que cumprem medida socioeducativa enquanto aguardam a disponibilidade de vagas nas unidades de internação oficiais.

O principal objetivo nesta pesquisa é identificar, mapear e analisar as condições socioespaciais dos bairros de Londrina, onde estão localizadas as residências dos adolescentes com passagem pelo CENSE I. Recorremos à pesquisa de natureza qualiquantitativa e, para o alcance do objetivo, inicialmente realizamos uma revisão bibliográfica sobre o tema da juventude em conflito com a lei, sobre a noção de espaço urbano, periferia e também sobre a cartografia do município de Londrina, dentre outras leituras. As fontes de consulta foram os livros e as publicações nas áreas de sociologia e geociências, além da legislação que trata sobre os direitos da criança e do adolescente. Concomitantemente, realizamos uma pesquisa de campo, que consistiu na coleta de dados sobre o lugar de moradia dos adolescentes com passagem pelo CENSE I no ano de 2009.

Tais dados foram extraídos dos prontuários de entrada dos adolescentes e dos dados estatísticos elaborados pela equipe técnica do CENSE I. Esses documentos encontram-se arquivados no setor de dados estatísticos da Unidade, os quais representam uma valiosa fonte de informações a respeito dos adolescentes com passagem pela instituição.

A análise documental, neste estudo, contribui para se constituir uma abordagem qualitativa, complementando e desvelando aspectos novos do tema, pois na análise busca-se identificar informações factuais nos documentos a partir das questões de interesse que permeiam estas relações (LUDKE; ANDRÉ, 1986, p. 39).

\footnotetext{
${ }^{1}$ Conforme prevê o ECA, se houver indícios de participação de adolescente na prática de ato infracional, a autoridade policial encaminhará ao representante do Ministério Público o relatório das investigações e demais documentos. O representante do Ministério Público deverá proceder a sua oitiva e poderá promover o arquivamento dos autos, conceder a remissão e representar à autoridade judiciária para aplicação de medida socioeducativa. A internação, decretada ou mantida pela autoridade judiciária, não poderá ultrapassar o prazo máximo de quarenta e cinco dias (BRASIL, 2006).
} 
Foram identificados todos os prontuários de entrada de adolescentes no ano de 2009 num total de 572 adolescentes atendidos, dos quais os dados sobre o lugar de moradia do adolescente e da família foram transcritos para um formulário em forma de tabelas, elaboradas pela equipe técnica do CENSE I. Posteriormente, esses dados serão apresentados em forma de gráficos e mapas, bem como analisados os seus conteúdos.

Aqui trabalhamos somente com os dados dos adolescentes atendidos pelo CENSE I, cujo local de moradia é a área urbana de Londrina, num total de 517 passagens. Desconsideramos os dados dos 55 adolescentes com residência em outros municípios, assim como dos residentes nos distritos e patrimônios rurais de Londrina.

Para o estudo deste espaço urbano, recorremos ao Atlas Urbano de Londrina (ARCHELA; BARROS, 2009) e ao Atlas Ambiental da Cidade de Londrina (BARROS et al., 2008), o que contribuiu para a análise e compreensão da cidade. O mapa é o principal instrumento de nossa pesquisa, juntamente com os dados colhidos na instituição.

Maria Cecília Minayo (1994) cita a preocupação do ser humano em se conhecer e conhecer a realidade na qual está inserido, bem como o status social que ocupa na sociedade.

\footnotetext{
Do ponto de vista antropológico pode se dizer que sempre existiu a preocupação do homo sapiens com o conhecimento da realidade. As tribos primitivas, através dos mitos, já tentavam explicar os fenômenos que cercam a vida e a morte, o lugar dos indivíduos na organização social com seus mecanismos de poder, controle, convivência e reprodução do conjunto da existência social (MINAYO, 1994, p. 24).
}

A autora analisa que a pesquisa social tem uma carga histórica e, assim como as teorias sociais, indicam posições frente à realidade, momentos do desenvolvimento e da dinâmica social, preocupações e interesses de classes e de grupos determinados. Indica ainda que a sociedade viva momentos históricos distintos, e que a pesquisa social não pode ser definida de forma estática. "Ela só pode ser considerada historicamente e entendendo-se todas as contradições e conflitos que permeiam seu caminho". Minayo vai mais além e cita que na pesquisa social a "realidade se apresenta como uma totalidade que envolve as mais diferentes áreas do conhecimento e também ultrapassa os limites da ciência" (MINAYO, 1994, p. 27).

Esta pesquisa, portanto, poderá subsidiar futuros projetos de inserção social de adolescentes em programas que contribuam com o seu desenvolvimento intelectual e 
profissional nas microrregiões de maior incidência de moradia desses adolescentes com passagem pelo CENSE I. Assim como pretende, também, contribuir com a prática cotidiana dos atores envolvidos no sistema de garantia de direitos da criança e do adolescente e com a construção de uma política voltada para a construção da cidadania.

Tendo em vista que a realidade é dinâmica e que o pesquisador deve estar atento às suas mudanças, é importante conhecer as noções e conceitos construídos sobre determinados fatos e aspectos da realidade.

A definição de espaço é deste modo essencial para esta pesquisa e, para isso, recorreu-se à discussão apresentada pelo geógrafo e pesquisador Milton Santos (1987, p. 58). Este destaca a importância de que "se saiba claramente a diferença entre aqueles que apenas dão importância às formas, estudando assim o espaço em si mesmo - são os 'espacialistas' - e aqueles que procuraram analisar o espaço nas suas relações com a sociedade (isto é através dos processos sociais, das funções e das formas) - são os 'espaciologos'”.

Na mesma linha de pensamento, Minayo (1994, p. 13) define o espaço como também sendo um objeto de criação e de transformação social.

\footnotetext{
O objeto das Ciências Sociais é histórico isto significa que as sociedades humanas existem num determinado espaço cuja formação social e configurações são especificas. Vivem o presente marcado pelo passado e projetado para o futuro, num embate constante entre o que está dado e o que está sendo construído. Portando, a provisoriedade, o dinamismo e a especificidade são características fundamentais de qualquer questão social.
}

Os espaços urbanos são, portanto, criações dos grupos sociais. À medida que se conhece o espaço e o tempo onde habita o ser humano, surge a necessidade de registrar esses conhecimentos e as alterações que produzem ao meio ambiente, e a cartografia é uma ferramenta básica tanto do desenvolvimento econômico quanto do desenvolvimento social.

Com o desenvolvimento tecnológico alcançado no último século, abriram-se várias possibilidades de representar o espaço. Na cartografia foram criadas inúmeras formas de representar a superfície terrestre, como os aspectos naturais, culturais e econômicos de determinada região, entre elas, as cartas que representam em escala média ou grande os aspectos naturais, artificiais e econômicos de determinada área, subdividida em folhas. 
Ela "constitui um mapa rico em detalhes usado para cartografar detalhes de uma área urbana, como exemplo os mapas de ruas" (TAMDJIAN; MENDES, 2005, p. 268).

Atualmente, as tecnologias de satélite passaram a fazer parte cada vez mais de nosso cotidiano, ampliando seus usos nas mais diversas áreas. Um exemplo da aplicabilidade da tecnologia do geoprocessamento, que está sendo muito difundido comercialmente e que tem aplicações, tanto no campo profissional como recreativo, é o GPS. Trata-se de uma tecnologia desenvolvida para ser utilizada na guerra e que hoje tem seu uso garantido nas mais diversas áreas, apresentando dados tão confiáveis quanto os da cartografia tradicional.

A cartografia, desse modo, constitui-se um importante instrumento de nossa pesquisa para o conhecimento do espaço de moradia dos adolescentes com passagem pelo CENSE I e para verificar se se concentra nas regiões periféricas ou não, e a sua localização social e espacial dentro do município de Londrina. Neste caminho, identificaremos e localizaremos cartograficamente os bairros onde residem os adolescentes e suas famílias.

O resultado deste estudo possibilitará aos gestores, órgãos governamentais e a sociedade em geral conhecerem as diversas situações presentes nos territórios que concentram a moradia de adolescentes com passagem pelo CENSE I, mobilizar recursos financeiros e humanos e propor uma linha de estratégias e políticas públicas que viabilizem ou mesmo definam ações com o intuito de prevenir o envolvimento de adolescentes em atos infracionais e que venham a evitar a reincidência daqueles adolescentes que já estão envolvidos. Como estabelece o ECA em seu artigo 4을

É dever da família da sociedade em geral e do poder publico assegurar com absoluta prioridade, a efetivação dos direitos à vida a saúde, a alimentação a educação ao esporte a profissionalização a cultura ao respeito à liberdade e à convivência familiar e comunitária (BRASIL, 2006, p. 4).

O ECA também prevê no art. 227, parágrafo único, alínea C, a "destinação privilegiada de recursos públicos as áreas relacionadas com a proteção a infância e a adolescência e a preferência na formação e na execução das políticas" (BRASIL, 2006, p. 4). 


\section{Perfil histórico de Londrina}

Londrina é uma cidade relativamente jovem. Surgiu nos anos 1930, com o processo de expansão das frentes pioneiras no norte do Paraná. Ela foi planejada para 20 mil habitantes, mas a sua população cresceu muito mais e de forma bastante rápida, principalmente por meio do processo migratório das áreas rurais para a cidade.

A periferia da cidade recebeu boa parte dessa população. Inicia-se, então, o surgimento das favelas. As mudanças estruturais no campo tiveram um impacto social muito profundo. A dissolução do sistema agrícola tradicional trouxe para a cidade, de modo geral, uma grande quantidade de pessoas sem posses, sem bens, nem dinheiro, com pouca ou nenhuma escolaridade, mas a favela os acolheu.

As ocupações irregulares não se localizam apenas nas áreas distantes do centro da cidade, mas ainda assim ocupam terrenos próximos aos fundos de vale e às nascentes de água que, apesar de protegidos por lei, são os mais atingidos. A ocupação dos fundos de vale é uma das principais preocupações da cidade, sendo considerada como área de preservação permanente.

O crescimento rápido da cidade, provocado pelo movimento migratório, fomentou e impulsionou o setor imobiliário.

\footnotetext{
A busca de lucros com as vendas dos lotes urbanos e a especulação imobiliária elevaram em muito o preço da terra, limitando o acesso por parte da população de baixa renda. Este foi também um dos fatores que motivaram a criação dos primeiros conjuntos habitacionais populares, alocados na periferia da cidade principalmente na região norte (ARCHELA; BARROS, 2009, p. 68).
}

Segundo Gislene Pereira (2001), a cidade apresenta desenvolvimento desigual, as benfeitorias realizadas agregam valores a terra, o que por si só já filtra a ocupação e o uso do solo, definindo locais e aglomerando povos de mesmo poder aquisitivo.

A cidade é fruto do processo de desenvolvimento capitalista que é essencialmente desigual, com "ilhas" de riqueza e áreas urbanas miseráveis. As diferentes localidades apresentam diferentes valores associados à acessibilidade aos bens e serviços. Concomitantemente, a distribuição espacial da população se dá de acordo com sua capacidade financeira de adquirir lotes em localização especificas e, através desse fato, ocorre a segregação social do espaço. Essa segregação é agravada pela especulação imobiliária, que ocorre estrategicamente para valorizar determinadas áreas (PEREIRA, 2001, p. 35). 
Demograficamente, Londrina é a quarta maior cidade do Sul do País, tornando-se polo regional, econômico, cultural e de serviços. Ainda em termos populacionais é a segunda cidade mais populosa do estado do Paraná, com 506.701 habitantes segundo censo demográfico de 2010 (IBGE, 2010).

A construção de conjuntos habitacionais pelo poder público também contribuiu para a intensificação e a expansão de outras formas de habitação: as ocupações irregulares (ARCHELA; BARROS, 2009, p. 77).

A Constituição Federal de 1988, em seus artigos 182 e 183, que tratam da política urbana, não define explicitamente o direito à moradia, mas estabelece que é dever do Estado, nas esferas Federal, Estadual e Municipal, "promover programas de construção de moradias e melhoria das condições habitacionais e de saneamento básico" (BRASIL, 2005).

Porém, a morosidade na promoção de programas de habitação de baixo custo para as populações de baixa renda, por parte dos governos, entre outros fatores, propicia o surgimento das chamadas ocupações irregulares. O que caracteriza a irregularidade destas áreas é o fato de elas estarem em desacordo com as leis municipais de uso e ocupação do solo urbano (Plano Diretor). Normalmente tais ocupações ocorrem em fundos de vale ou na periferia da cidade, mas também podem ocorrer na área central, dependendo do contexto histórico social, de origem.

$\mathrm{Na}$ busca pela segurança em um espaço diferenciado, onde a qualidade de vida e a moradia sejam priorizadas, inicia-se na década de 1990 a implantação de condomínios fechados horizontais em algumas regiões periféricas da cidade onde habitam uma pequena parcela da população. Ocorre então um deslocamento da população de maior poder aquisitivo para a "periferia", por opção.

Sobre a produção do espaço urbano, Milton Santos (1987, p. 81) pondera que:

Cada homem vale pelo lugar onde está; o seu valor como produtor, consumidor, cidadão depende de sua localização no território. Seu valor vai mudando incessantemente, para melhor ou para pior, em função das diferenças de acessibilidade (tempo, freqüência, preço) independentes de sua própria condição. Pessoas com as mesmas virtualidades, a mesma formação, até mesmo salário, tem valor diferente segundo o lugar em que vivem: as oportunidades não são as mesmas. Por isso, a possibilidade de ser mais ou 
menos cidadão depende, em larga proporção, do ponto do território onde se está.

A produção do espaço urbano pela ação do ser humano gera problemas ambientais que advêm não apenas das relações entre a sociedade e a natureza, mas também das relações entre os próprios seres humanos.

\section{Análise dos dados}

Dentre os 572 adolescentes com passagem pelo CENSE I, 53 vieram de outros municípios, sendo 27 de Cambé, 11 de Ibiporã e, na sequência, 04 de Maringá, 02 de Tamarana, 02 de Rolândia e 01 adolescente de cada uma das cidades de Andirá, Paiçandu, Paranavaí, Embaú, Mauá da Serra e Arapongas, no estado do Paraná, e 01 adolescente de Jaraguá do Sul, em Santa Catarina. Dos Patrimônios Regina e Heimtal, de Londrina, 02 adolescentes passaram pelo CENSE I.

A transferência de outro município dependia da disponibilidade da Central de Vagas do órgão responsável pelas unidades de socioeducação à época, a Secretaria de Estado da Criança e Juventude - SECJ. São poucos os casos e, embora pareça ser prejudicial deslocar um adolescente de sua cidade de origem, afastando-o de seus familiares, tornando as visitas das famílias mais difíceis, às vezes, essas atitudes são tomadas para a proteção do adolescente.

Aqui trabalhamos somente com os dados referentes aos adolescentes que passaram pelo CENSE I em 2009, cujo local de moradia é um bairro da área urbana de Londrina, que totalizam 517 habitantes. Desconsideramos, portanto, os dados dos 53 adolescentes de outras cidades assim como dos 02 adolescentes dos patrimônios rurais de Londrina.

A partir de 1990, o número de ocupações irregulares aumentou muito. A região Sudeste de Londrina concentra as maiores ocupações irregulares em termos populacionais, assim como a exclusão socioespacial, principalmente no bairro União da Vitória e Saltinho, onde a topografia acidentada desvaloriza os terrenos.

Ao utilizarmos o mapa da Área Urbana de Londrina, optamos pelo mapa de zoneamento que, com base no IBGE, facilita e melhora a visualização dos locais de moradia dos adolescentes com passagem pelo CENSE I, como pode ser visto no mapa a 
seguir (Figura 1), reproduzido do Atlas Ambiental da Cidade de Londrina (BARROS et al., 2008).

Figura 1 - Divisão Regional da área Urbana de Londrina por bairros e por regiões (Grifo do pesquisador)

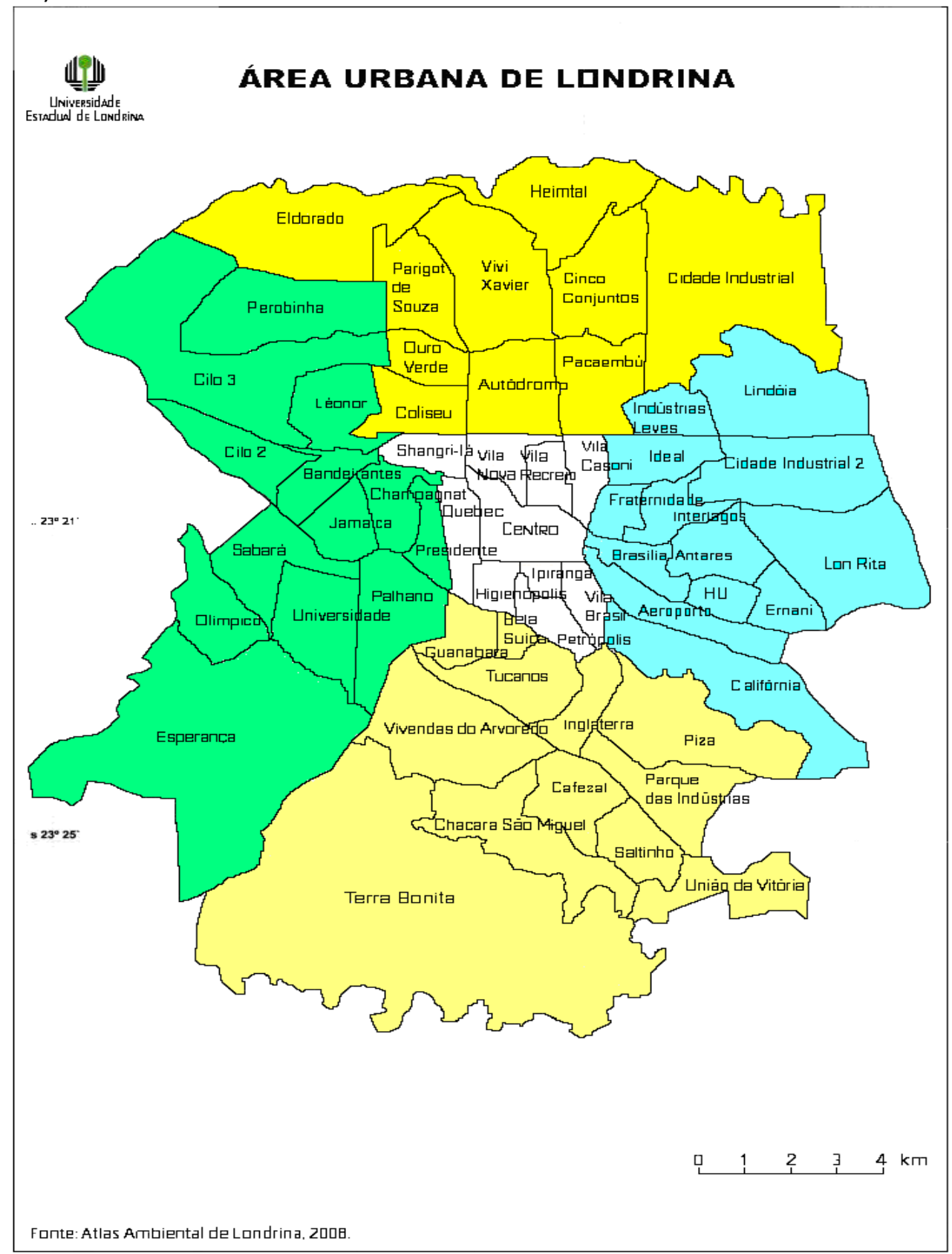

Fonte: Atlas Ambiental da Cidade de Londrina (BARROS et al., 2008).

No mapa seguinte (Figura 2), podemos visualizar como estão distribuídos os locais de moradia dos adolescentes com passagem pelo CENSE I. Percebemos que nas áreas mais claras não encontramos nenhuma moradia e, gradativamente, à medida que as cores vão ficando mais fortes aumentam os locais de residência naquela área. Outro fator 
importante que observamos é que algumas áreas de grande incidência de moradias não estão localizadas na periferia da cidade, mas sim em locais próximos a área central, como é o caso dos jardins Ideal e Interlagos, áreas com ocupações irregulares e que já passaram ou estão passando por um processo de urbanização, e a área dos Cinco Conjuntos, que aglomera alguns bairros onde reside uma população em situação de pobreza. Os serviços de infraestrutura ainda são precários, mas melhores do que nas áreas de ocupação irregular.

Figura 2 - Mapa da área Urbana de Londrina, por região bairros e concentração de moradias de adolescentes com passagem pelo CENSE I

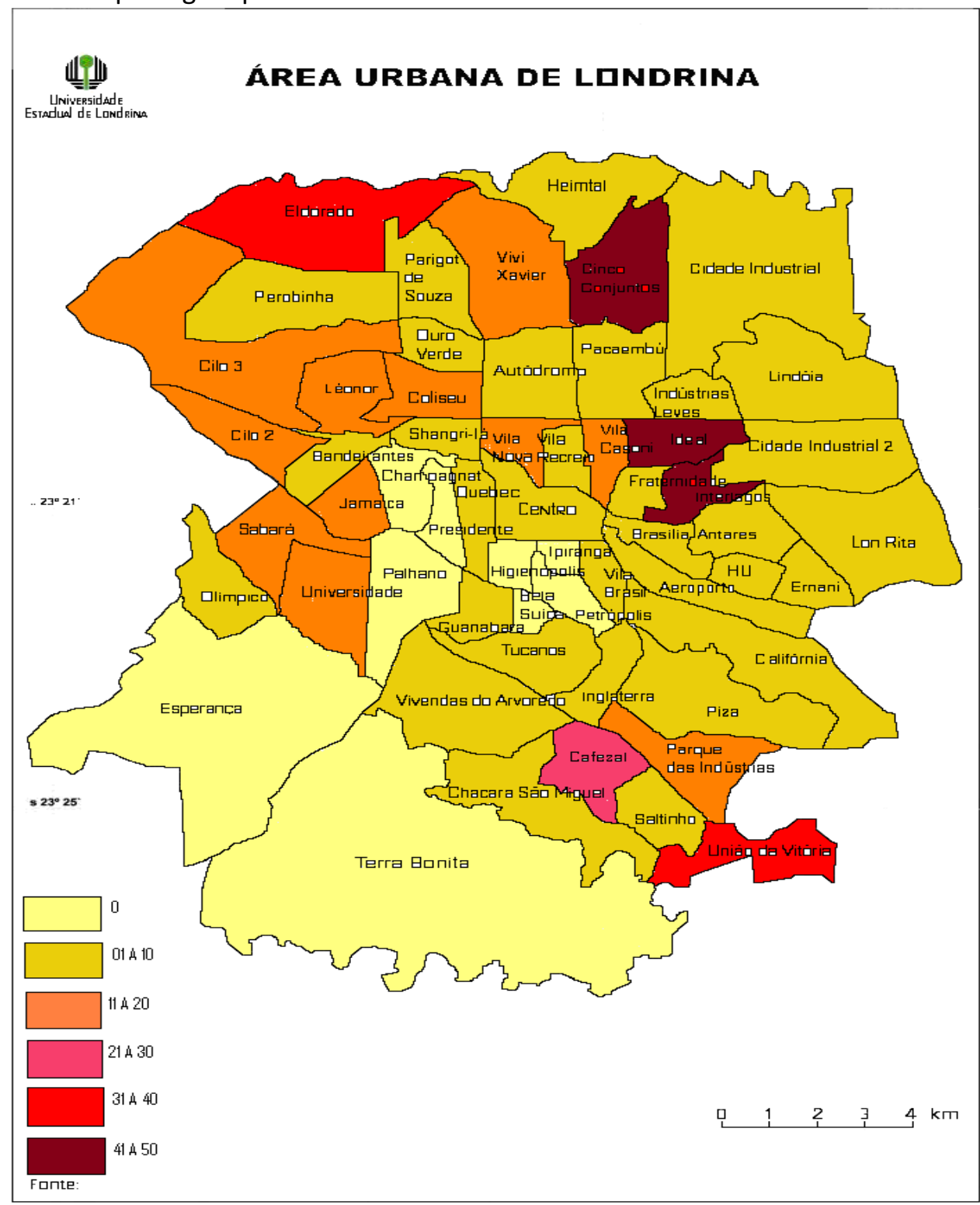

Fonte: Dados coletados nos prontuários do CENSE I em 2010 e organizados pelo pesquisador e adaptado do Atlas Ambiental da Cidade de Londrina (BARROS et al., 2008). 
As regiões Norte e Leste concentram os maiores índices de residências de adolescentes com passagem pelo CENSE I.

Dione Lolis (2008, p. 188), cita que as características dos lugares de moradia dos jovens vítimas de homicídios na cidade de Londrina, de um modo geral, apresentam acúmulo de carências, entre elas pobreza, vida em condição de miséria, baixa escolaridade, evasão escolar, pouca ou nenhuma infraestrutura.

Na região Norte da cidade, encontra-se uma grande quantidade de moradias construídas pelas companhias de habitação dos governos federais e estaduais durante anos, para os grupos sociais de menor poder aquisitivo, são as chamadas casas populares ou conjuntos populares. As casas são padronizadas, construídas em alvenaria com uma infraestrutura básica de tamanho variável, mas relativamente pequenas, contendo dois quartos, sala, cozinha, banheiro e área de serviço. Os terrenos têm em média duzentos metros quadrados. A princípio, as moradias foram construídas longe da região Central, reservando assim grandes áreas destinadas à especulação imobiliária, que ao longo dos anos foram sediadas por ocupações residenciais e industriais.

A região Norte é uma região densamente povoada. No gráfico a seguir apontamos as áreas ocupadas pelos bairros e a quantidade de moradias de adolescentes com passagem pelo CENSE I em cada bairro.

Gráfico 1 - Locais de moradia de adolescentes com passagem pelo CENSE I em 2009, na região Norte de Londrina

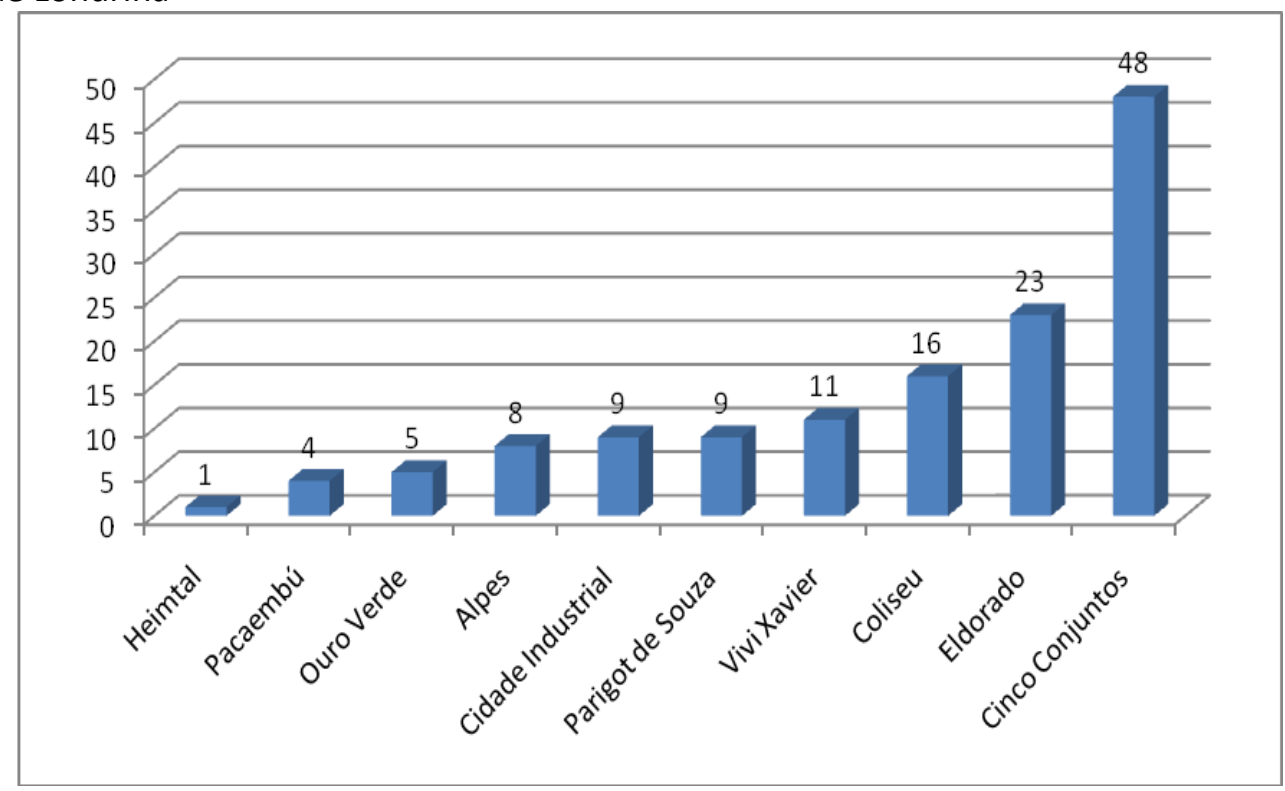

Fonte: Dados coletados nos prontuários do CENSE I em 2010 e organizados pelo pesquisador. 
Os bairros que compõem a região Norte da cidade de Londrina são, conforme o Atlas Urbano da Cidade de Londrina (ARCHELA; BARROS, 2009, p. 84), Jardim Eldorado, Parigot de Souza, Ouro Verde, Coliseu, Vivi Xavier, Alpes, Pacaembu, Cinco Conjuntos, Heimtal e Cidade Industrial. Nesta região, encontramos 134 registros de moradias de adolescentes com passagem pelo CENSE I em 2009, sendo que os bairros Jardim Coliseu, Eldorado e Cinco Conjuntos, foram os que apresentaram maior quantidade de residências, com 16, 23 e 48 moradias, respectivamente, seguidos pelo conjunto Vivi Xavier, com 11 moradias.

A região mostrada no mapa Área Urbana de Londrina (Figura 2) denominada "Cinco Conjuntos" é onde estão localizados os seguintes e principais bairros: Conjunto Habitacional Aquiles Sthenguel, Jardim dos Campos, Jardim Primavera, Conjunto Luiz de Sá, Jardim D. Vicente, Jardim Aliança, Conjunto Maria Cecília, Jardim Campos Verdes, Jardim Belém, Jardim, Novo Horizonte, Jardim Santa Cruz, Jardim Itapuã e Loteamento Strass.

Alguns destes bairros são constituídos por uma população extremamente pobre e com graves problemas sociais, como o assentamento Jardim São Jorge e o conjunto habitacional José Belinati, destinados ao desfavelamento. Este último faz parte da área dos Cinco Conjuntos, e suas casas foram construídas para receber moradores de locais considerados irregulares, de acordo com a legislação do município.

$\mathrm{Na}$ região Leste, como é possível verificar no gráfico a seguir (Gráfico 2), encontramos o maior número de adolescentes com passagem pelo CENSE I em bairros como Ideal e Interlagos. 
Gráfico 2 - Locais de moradia de adolescentes com passagem pelo CENSE I em 2009, na região Leste de Londrina

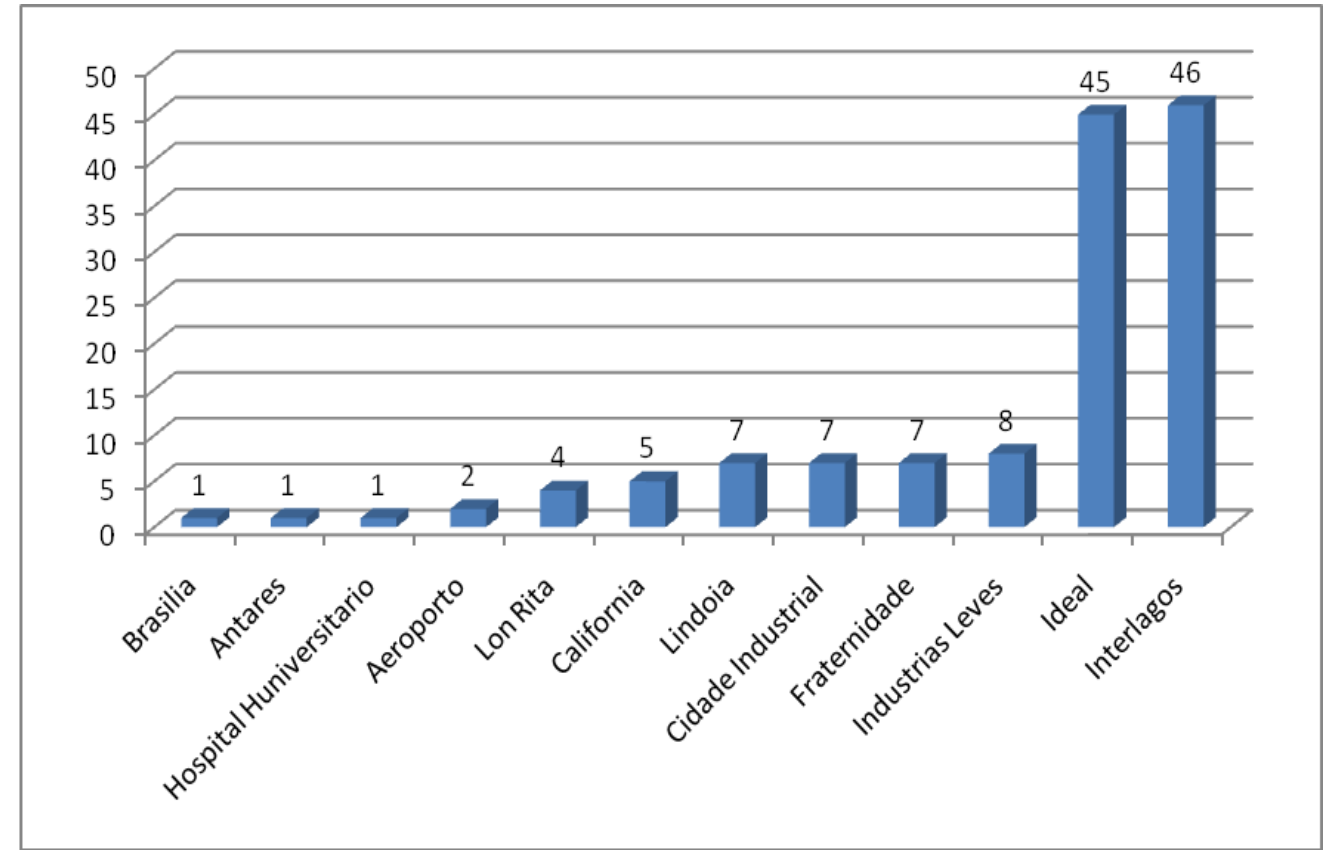

Fonte: Dados coletados nos prontuários do CENSE I em 2010 e organizados pelo pesquisador.

A região Leste, assim como a região Norte, apresenta uma grande concentração populacional. Os principais bairros que compõem esta região são: Jardim Brasília, Antares, Hospital Universitário, Aeroporto, Lon Rita, Califórnia, Lindóia, Cidade Industrial 2, Fraternidade, Indústrias Leves, Jardim Ideal e Interlagos. Esta difere da região Norte na quantidade de ocupações irregulares, algumas das quais já em vias de regularização, frequentemente localizadas às margens dos córregos.

As maiores ocupações e assentamentos da região Leste são: Santa Fé, Monte Cristo e Rosa Branca. São áreas que apresentam saneamento básico precário, geralmente ocupadas por uma população com baixo acesso aos direitos formais, e são áreas consideradas aptas a serem regularizadas segundo o Instituto de Pesquisa e Planejamento Urbano de Londrina - IPPUL (LONDRINA, 2008). Estas ocupações, junto com o Jardim Marabá, compõem o Jardim Ideal, que registrou 45 passagens de adolescentes pelo CENSE I.

Na região Leste, localizamos 134 residências de adolescentes com passagem pelo CENSE I. Só na área denominada de Jardim Interlagos, composto pelos bairros: Vila Ricardo, Jardim Meton, Jardim Laranjeiras, Jardim Santa Maria, Jardim Taliana e Jardim Sérgio Antonio, encontramos 46 residências de adolescentes com passagem pelo CENSE I. 
Os bairros que compõem a área denominada de Fraternidade são: a Vila da Fraternidade, conjuntos habitacionais Pindorama I e II, Jardins Rafael e Carlota. Os conjuntos habitacionais Pindorama I e II, bem como o Conjunto Novo Amparo, localizado na grande área das Indústrias Leves, e o Vale do Cambézinho, pertencente à área do jardim Califórnia, foram construídos com o objetivo de desfavelar e urbanizar áreas de ocupação irregular e sem infraestrutura básica.

Boa parte da população residente em áreas de ocupações irregulares sofre com a presença de grupos ligados ao tráfico de drogas e ao crime. A mídia veicula, com frequência quase que diária, os crimes como homicídio, atribuídos a acertos de contas e outros tipos de agressões, provenientes dessas áreas.

Encontramos na região Leste alguns bairros com uma representatividade relativamente baixa de domicílios de adolescentes com passagem pelo CENSE I, são eles: Jardim Brasília, Antares, Hospital Universitário, Aeroporto e Lon Rita.

O gráfico seguinte apresenta os dados da região Sul, de acordo com as áreas, sua composição por bairros e a concentração de moradias de adolescentes com passagem pelo CENSE I em cada bairro.

Gráfico 3 - Locais de moradia de adolescentes com passagem pelo CENSE I em 2009, na região Sul de Londrina

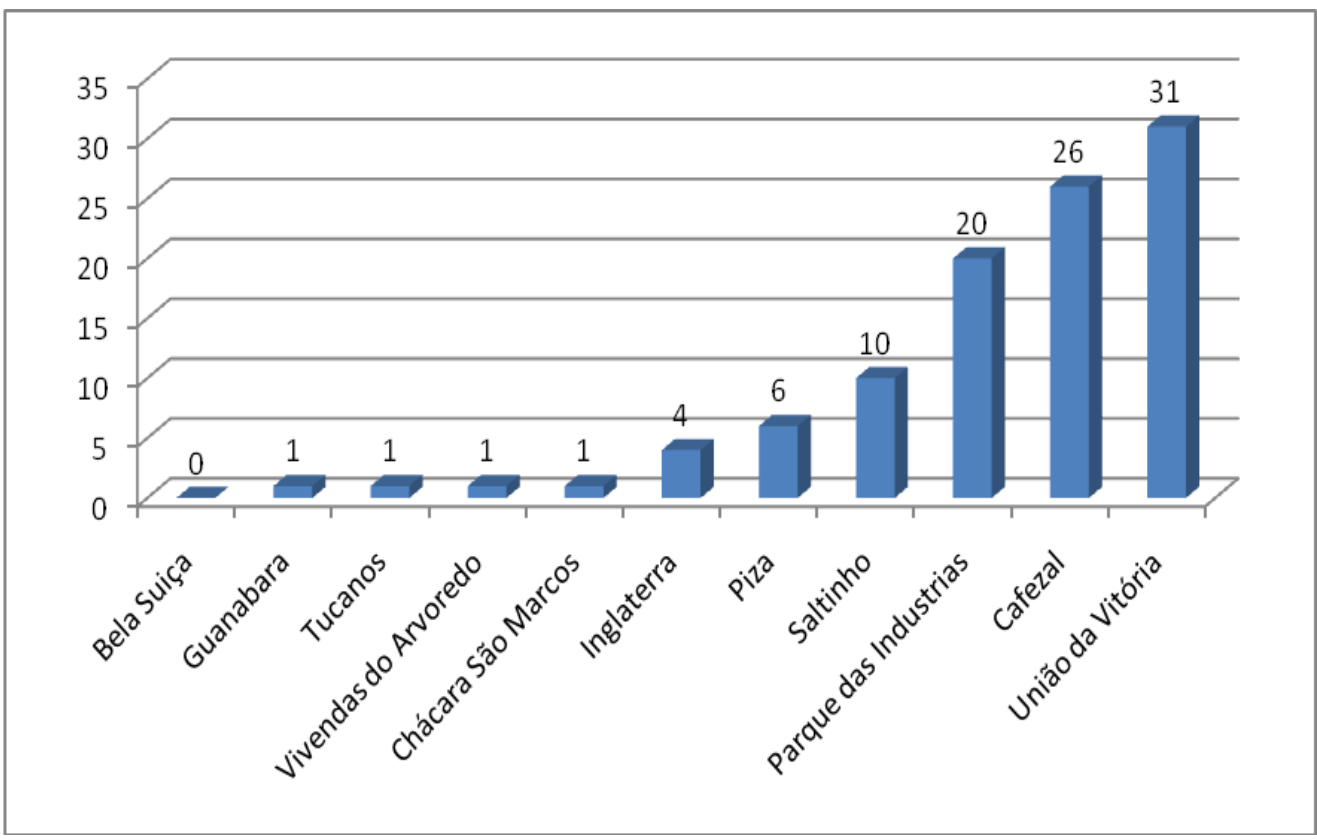

Fonte: Dados coletados nos prontuários do CENSE I em 2010 e organizados pelo pesquisador. 
A região Sul é composta pelos bairros: Jardim Bela Suíça, Guanabara, Tucanos, Vivendas do Arvoredo, Chácara São Miguel, Inglaterra, Pizza, Saltinho, Parque das Indústrias, Cafezal e Jardim União da Vitória.

Os bairros que apresentaram menos domicílios de adolescentes com passagem pelo CENSE I são: Guanabara, Tucanos, Vivendas do Arvoredo, Chácara São Miguel e Inglaterra, todos com apenas uma moradia de adolescentes que tiveram passagem pelo CENSE I em 2009. Já os bairros Parque das Indústrias, Cafezal e União da Vitória, concentram o maior número de moradias. O Jardim Bela Suíça é o único bairro na região Sul que não conta com adolescentes com passagem pelo CENSE I.

Os bairros que compõem a área denominada União da Vitória (maior assentamento populacional de famílias oriundas de ocupações irregulares da cidade, realizado pelo poder público), estão localizados no extremo Sul do Município e, na medida em que foram se expandindo, várias ocupações foram surgindo, sendo assim denominados desde o I ao VI. Nesta área, localizamos 35 moradias de adolescentes com passagem pelo CENSE I.

Ainda na região Sul, a área denominada como Jardim Franciscato é formada, além deste, pelos bairros Jardim Novo Perobal, Jardim Santa Joana e Conjunto São Lourenço, sendo que alguns deles são considerados pelo Município como aptos a serem regularizados, por se tratarem de ocupações espontâneas e irregulares (LONDRINA, 2008).

Os bairros citados como os de maior incidência de adolescentes com passagem pelo CENSE I correspondem à área da região Sul com maior concentração de pobreza e maior precariedade ou ausência de condições de acesso aos direitos essenciais. Nos demais bairros da região não foram registrados números significativos de passagens pela Unidade.

A região Oeste também apresenta um alto número de passagens de adolescentes pelo CENSE I, como verificamos nos dados do gráfico a seguir. 
Gráfico 4 - Locais de moradia de adolescentes com passagem pelo CENSE I em 2009, na região Oeste de Londrina

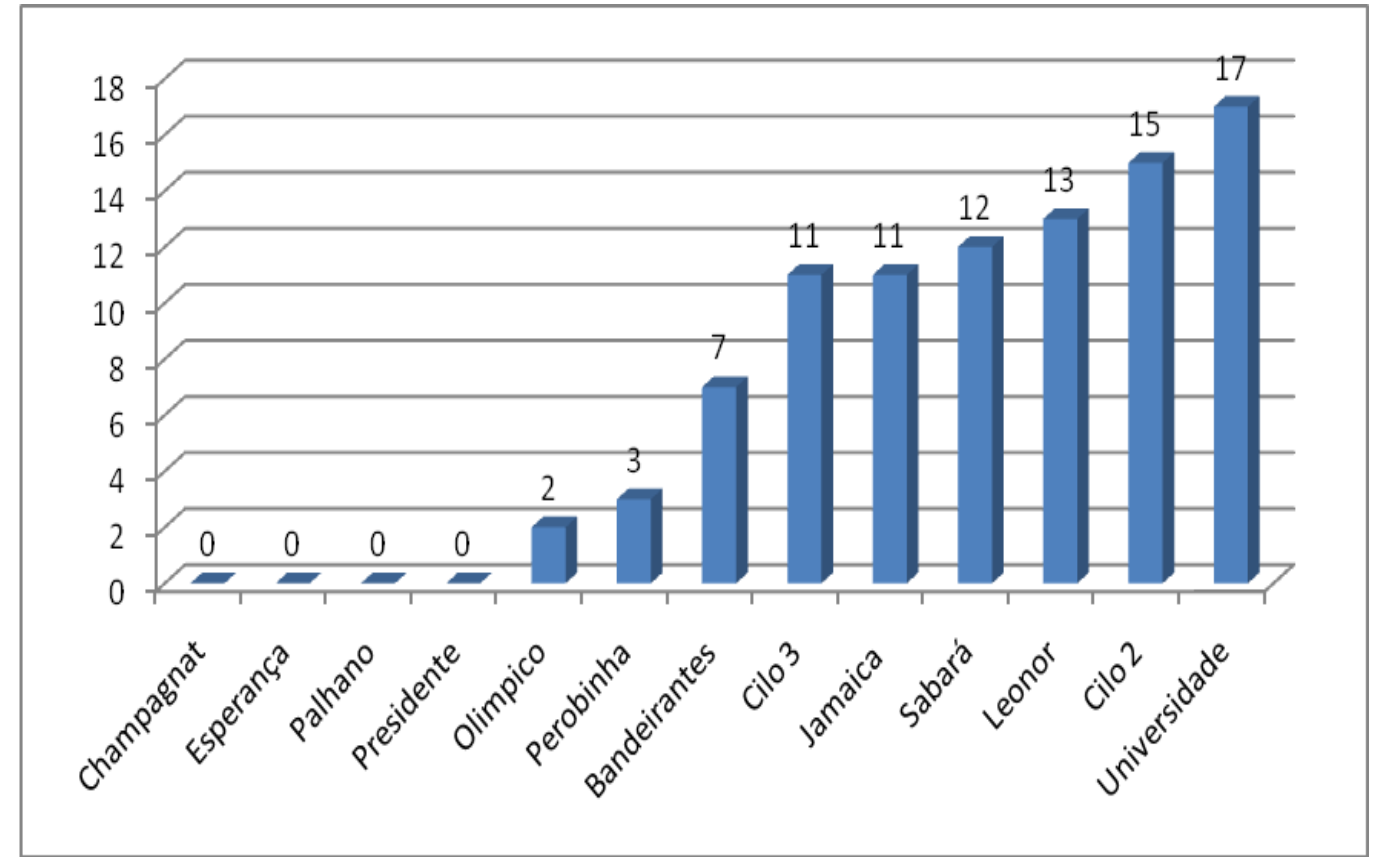

Fonte: Dados coletados nos prontuários do CENSE I em 2010 e organizados pelo pesquisador.

Os bairros que compõem a região Oeste de Londrina são: Perobinha, Cilo 3, Leonor, Cilo 2, Bandeirantes, Jamaica, Sabará, Universidade, Olímpico, Champagnat, Presidente, Esperança e Palhano.

Na região Oeste, encontramos 98 residências de adolescentes com passagem pelo CENSE I. Nesta área, estão bairros como o João Turquino, Maracanã I e II e o Londriville, Campos Verdes (este conurbado à cidade de Cambé), densamente povoados, cuja ocupação se deu de forma irregular, onde a população sofre com a falta de infraestrutura básica e as moradias são relativamente precárias. Alguns destes bairros já estão em via de regularização junto à prefeitura do município e o maior agravante nesta área é que se trata de um local de fronteira entre dois municípios (Londrina e Cambé), e o atendimento nos serviços públicos essenciais é deficitário devido à divisão política.

Os bairros onde encontramos as maiores concentrações de residências de adolescentes com passagem pelo CENSE I são, segundo os dados coletados, Universidade, Sabará e Cilo 2, com 17, 12 e 15 moradias, respectivamente.

Contrastando com as áreas com a presença de ocupações irregulares e muito pobres, ainda na região Oeste, encontramos bairros com ótima infraestrutura e neles 
também não estão nenhuma residência de adolescentes com passagem pelo CENSE I. Os bairros que fazem parte desta área são: Champagnat, Presidente, Esperança e Palhano.

A região Central da cidade foi a que apresentou menor número de residências de adolescentes com passagem pelo CENSE I, conforme se verifica a seguir.

Gráfico 5 - Locais de moradia de adolescentes com passagem pelo CENSE I em 2009, na região Central de Londrina

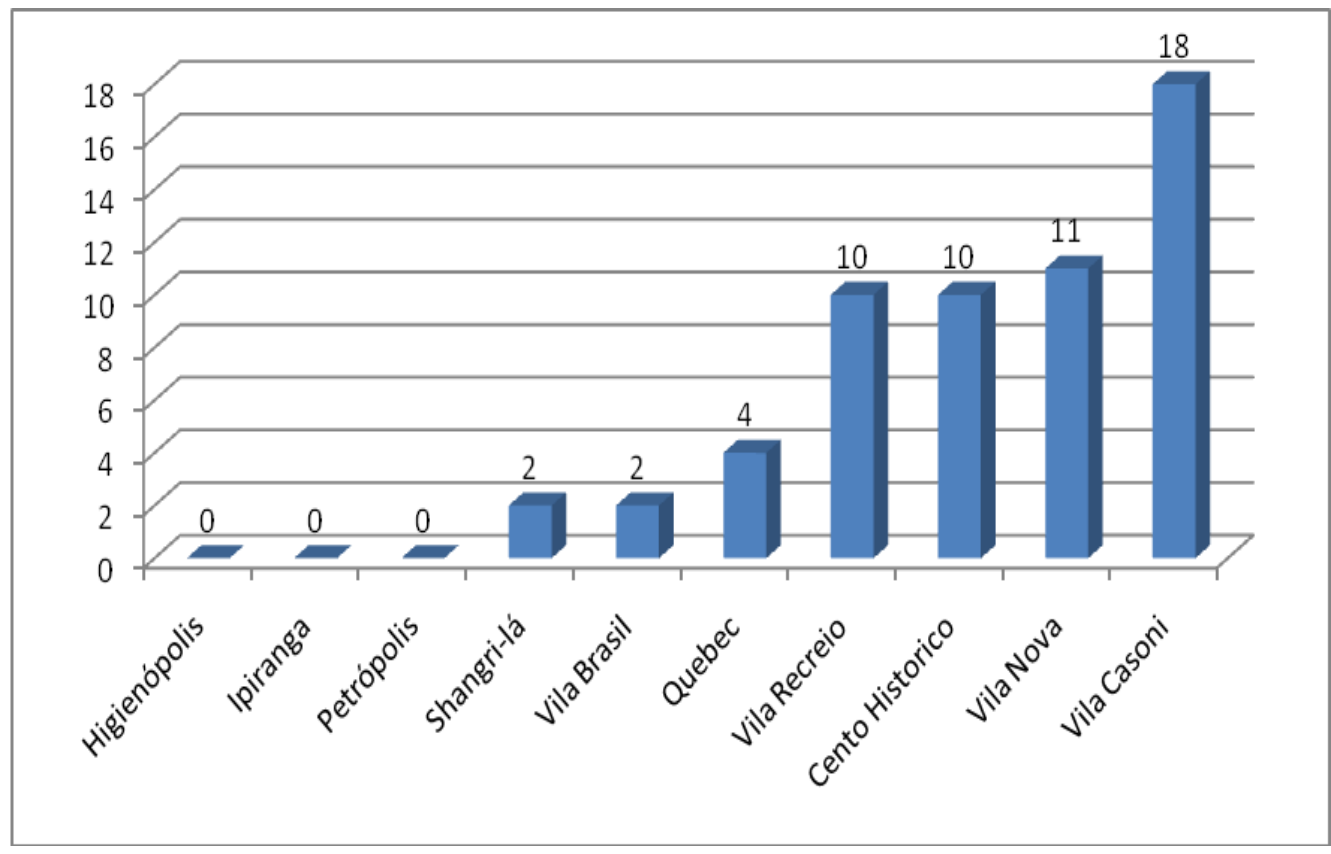

Fonte: Dados coletados nos prontuários do CENSE I em 2010 e organizados pelo pesquisador.

Compõem a região Central os seguintes bairros: Shangri-lá, Vila Nova, Vila Recreio, Vila Casoni, Jardim Quebec, Centro Histórico, Vila Brasil, Higienópolis, Jardim Ipiranga, Jardim Petrópolis.

A região Central concentra a maioria dos estabelecimentos comerciais do município. Comercialmente, Londrina é uma cidade que tem grande influência desde a região metropolitana até o Sul do estado de São Paulo, atraindo compradores de muitas cidades vizinhas, assim como também se sobressai a área de prestação de serviços, especialmente no atendimento à saúde.

Esta é uma região densamente povoada e, por ser central, é grande o fluxo de pessoas como também de muitas ocorrências policiais. Apesar disso, encontramos apenas 57 residências de adolescentes com passagem pelo CENSE I. Este número é pequeno quando comparado ao das outras regiões de Londrina. 
Na região Central, os locais onde mais encontramos residências de adolescentes autores de ato infracional com passagem pelo CENSE I são: Vila Casoni, Vila Nova, Vila Recreio e Centro Histórico, com 18, 11 e 10 moradias, respectivamente.

Existem algumas ocupações irregulares na região Central e algumas estão localizadas em fundos de vale, que são: Favela Vila Marizia e Favela Quati. A favela Vila Marizia está apta a ser regularizada, segundo o IPPUL (LONDRINA, 2008), fruto de algumas ações realizadas por parte do governo local, na tentativa de minimizar os problemas sociais relacionados às ocupações irregulares, tais como a construção de conjuntos habitacionais destinados ao desfavelamento. Outras áreas consideradas irregulares na região já passaram por esse processo, a exemplo do Conjunto Habitacional Barra Vento.

\section{Considerações finais}

Em linhas gerais, as informações permitem constatar que as regiões Norte e Leste concentram uma grande quantidade de moradias de adolescentes com passagem pelo CENSE I de Londrina no ano de 2009. Muitos desses locais de moradia encontram-se em áreas não regularizadas e outras em via de regularização.

Embora a cidade tenha crescido, os bairros que compõem a região Norte de Londrina, junto com os bairros da região Leste, lideram em número de moradias de adolescentes que foram apreendidos por ato infracional e passaram pelo CENSE I, principalmente nas áreas que mais concentram famílias residindo em condições precárias.

Na região Leste, a maior concentração se dá em locais de ocupações irregulares e mais próximas à região Central, como é o caso dos bairros que compõem o Jardim Ideal e o Jardim Interlagos.

Na região Sul, os bairros que se sobressaem com maior número de moradias de adolescentes com passagem pelo CENSE I são os que compõem o Cafezal, Saltinho, Parque das Indústrias e União da Vitória. Este último, mesmo com algumas melhorias feitas pelo poder público, conta com novas ocupações irregulares e apresenta uma precária infraestrutura. Ele compõe a área que mais concentra problemas sociais na cidade. 
Nas demais regiões, Oeste e Centro, fizemos a mesma verificação. Onde as condições de vida de determinados grupos populacionais são mais precárias concentramse as moradias de adolescentes com passagem pelo CENSE I.

Os dados indicam que nas áreas da cidade no qual o Estado é quase ausente ou pouco atuante foi onde encontramos o maior número de residências de adolescentes com passagem pelo CENSE I. Consideramos que é preciso mudar o quadro aqui apresentado e que o Estado, por meio de políticas sociais públicas, em todos os âmbitos, atue no sentido de melhorar as condições de moradia existentes, melhorar a infraestrutura básica nesses bairros, investir mais em educação em todos os níveis, oferecendo, inclusive, ensino técnico e profissionalizante, próximo aos bairros que mais concentram esses adolescentes.

\section{Referências}

ARCHELA, R. S.; BARROS, M. V. F. (Org.). Atlas urbano de Londrina. Londrina: EDUEL, 2009.

BARROS, M. V. F. et al. (Org.). Atlas ambiental da cidade de Londrina 2008: mapas e textos. Londrina: UEL. 2008. Disponível em:

<http://www.uel.br/revistas/atlasambiental/>. Acesso em: 8 dez. 2011.

BRASIL. Constituição (1988). Constituição da República Federativa do Brasil. São Paulo: Saraiva, 2005.

. Estatuto da criança e do adolescente. Curitiba: Imprensa Oficial, 2006.

IBGE. Cidades. 2010. Disponível em:

<http://www.ibge.gov.br/cidadesat/xtras/perfil.php?codmun=411370\&r=2>. Acesso em: 29 nov. 2011.

LOLIS, D. Um jeito jovem de morrer: homicídios de jovens por armas de fogo em Londrina, 2000-2003. 2008. Tese (Doutorado em Sociologia) - Universidade Estadual Paulista Júlio de Mesquita Filho (Campus de Araraquara), Faculdade de Ciências e Letras, Programa de Pós-Graduação em Sociologia, Araraquara.

LONDRINA. Instituto de pesquisa e planejamento urbano de Londrina. 2008. Disponível em:

$<$ http://www1.londrina.pr.gov.br/index.php?option=com_content\&view=article\&id=587 \&ltemid=705>. Acesso em: 17 nov. 2011.

LUDKE, M.; ANDRÉ, M. E. D. A. Pesquisa em educação: abordagens qualitativas. São Paulo: Pedagógica e Universitária, 1986. 
MINAYO, M. C. S. Ciência, técnica e arte: o desafio da pesquisa social. In: (Org.). Pesquisa social: teoria, método e criatividade. 8. ed. Petrópolis: Vozes, 1994. p. 9-29.

PEREIRA, G. A. A natureza (dos) nos fatos urbanos: produção do espaço e degradação ambiental. Desenvolvimento e Meio Ambiente, Curitiba, n. 3, p. 33-51, jan./jun. 2001.

SANTOS, M. O espaço do cidadão. São Paulo: Nobel, 1987.

TAMDJIAN, J. O.; MENDES, I. L. Geografia geral e do Brasil. São Paulo: FTD, 2005. (Estudos para a compreensão do espaço).

Recebido em: 03/10/2011

Aprovado em: 30/10/2011 